\title{
1. The home: multidisciplinary reflections
}

\section{Antonio Argandoña}

\section{INTRODUCTION $^{1}$}

In 1999, Colombia, the world's leading cocaine producer, launched the Colombia Plan, an initiative by the United States government to drastically reduce coca production in that country, mainly by aerial spraying of coca fields. This led to a major part of cocaine production being moved to Peru, distorting the economic incentives of farmers in the areas where this crop could be grown. As a result, child labor grew in these tasks, increasing the school dropout rate. Children learned about the business of making and selling drugs, and acquired new skills in tasks that earned them money but put them outside the law. Many of them joined illegal organizations and their involvement in criminal activities increased, generating new cycles of dysfunctional families, and leading to loss of social capital and increased criminality. These are just some among many effects, the consequences of which persisted for many years.

All of this is well known to scholars of subjects such as drug production and distribution, school failure, destabilization of family environments, the rise of criminal organizations, changes in countries' production structure and comparative advantages, the opportunities for underground economy, the skills in demand on the job market, changing values in society, and so on. However, there are not many inclusive discussions of these subjects, saving a few exceptions (Sviatschi, 2017). This raises the risk of proposing partial solutions that cannot work together and ultimately become counterproductive.

The customary way in which these issues are addressed in academic papers and, often, in policy proposals as well, is to set certain concrete objectives, pool the analyses contributed by different disciplines and look for compatible solutions. This interdisciplinary approach may be useful when the problems are relatively simple. But if the problem is very 
complex, such as the one mentioned above, and creates dynamics that perpetuate over time, the analysis must be consistent from the very first steps.

Our proposal is that the home could be a useful unit of analysis because all of the problems we have mentioned are ultimately projected on a community of people (a family) who live together in a place (a house), with a more or less explicitly shared common project (the social function of the home) in a particular setting (a village in a rural county open to domestic and foreign markets). All of these problems affect people_not abstract individuals or people living in isolation, but people who form communities, starting with the most elementary and probably the most important community of all: the family. If we are interested in these problems, the home is probably the right place to start the analysis. ${ }^{2}$

The main reason for the relevance of the home approach is its role in defining that community's social purpose or function. In the example given above, it is likely that public interventions will be implemented, for example, to deter cocaine production, minimize school dropouts or keep young people away from criminal organizations. But these cannot be ultimate goals: such goals must take into account people's dignity, their human, professional and moral development, and the creation of the necessary conditions for functional, stable, prosperous homes. In other words, the experts who propose solutions and the politicians who endorse them must always bear in mind the impact that all of this will have on the institution we call the home, because that is the best way to take into account the impact on people, who must be the ultimate target of their actions. $^{3}$

Using the home as the center of analysis does not necessarily mean creating specialized studies on this subject, or advocating a 'science of the home'. What we are proposing here is that the analysis of many societal and human problems can be given added width and breadth if the home is put at its core.

This chapter offers a short analysis of these phenomena. After a brief introduction on how we envisage the study of the home, we will go on to describe what the home is, both in its internal components and in its relations with society, emphasizing what we call the internal and external functions of the home. We will then present some of its main dimensions - temporal, spatial, economic and ethical-which, in fact, accommodate many other dimensions, and will end by drawing some conclusions. 


\section{THE STUDY OF THE HOME}

The home has been a subject for study by philosophy and social sciences since ancient times, as a reality that is present in all places and at all times, albeit under very different forms, and with very different roles and characters. Each of these disciplines has been constructed on different assumptions, uses different methods and techniques and offers partial views (economic, psychological, sociological) or, at best, comparisons of the phenomena from the viewpoint of several disciplines. The danger of these specialized approaches is that their conclusions can be misinterpreted by other disciplines, their results are sometimes not comparable, and their language is not always comprehensible to other researchers.

In our view, the study of the home requires the following features:

- A multidimensional approach, because the issues do not appear in isolation but are interrelated. School failure, difficulty in finding a good job or the repetition of damaging family models in future generations is not just an educational or an economic or a medical problem but draws from both these and other dimensions (Burns, 2018; Davey Smith et al., 2001; Sclar and Northridge, 2003; Shaw, 2004).

- A multidisciplinary approach, rather than an interdisciplinary one. Research is interdisciplinary when experts from various fields are faced with a topic of study, each from their own assumptions and methods; the interdisciplinary character of the project leads to mixed hypotheses, shared methods or comparisons of results. But when the research is multidisciplinary, the experts try to develop new models, tools and methods based on common hypotheses, shared languages and expanded conceptions, which are not possible, or are difficult to achieve if each remains within their original area of competence. This requires an effort to understand others' positions, not from the discipline's internal assumptions but from those of others, thinking simultaneously from each discipline (MacIntyre, 1990).

- Therefore, an integrative approach, linking together the various issues not only after the study has been completed, but also from its early stages.

- A global focus, which nevertheless does not lose sight of the local, concrete and specific. We talk about the home in the singular, but it is an empirical fact that there are many-almost infinite-varieties of homes, with different features but also with some common 
elements. ${ }^{4}$ 'The home is apprehended ... as a reality not foreign to human nature, and therefore ... not a merely convenient artificial construct' (d'Entremont, 2018).

- Openness to different theoretical, conceptual and, of course, ideological premises. This does not mean that the approach should be eclectic or relativistic: the researcher will have his or her own hypotheses and assumptions, but should also be open to the arguments made by those who do not think like him or her, in order to understand, for example, whether they address differences about facts (or assumed facts), hypotheses, constraints (for example, what can be feasible in a given situation) or values (or, more commonly, the application of values to specific situations).

- A discourse that is descriptive (trying to understand what $i s$ ), but often also normative (emphasizing what must be, or trying to understand why sometimes the home does not meet the normative specifications). Given the significance of our subject of analysis, the normative proposals should explain at least: (1) the hypothesis, (2) the data and its interpretation, and (3) the valuation criteria.

- The designation of public or private actions to correct or improve a situation. Here too, it is important to make explicit: (1) the assumptions, (2) the objectives, and (3) the constraints on which these interventions are based.

According to George (2015), a prosperous, ethical society is supported on five pillars: (1) the person, (2) the family, (3) a just and effective system of legislation and government, (4) efficient educational institutions, and (5) an economic system based on the firm and the market. The study of the home is concerned with the first and second of these pillars, but it also has implications and connections with the other three.

\section{THE HOME}

There is no single definition of home, nor a more or less complete list of its functions or tasks. ${ }^{5}$ The concept of the home focuses on three internal elements: the person, the inner community or family, and shared living space with an intention of continuity. But there is also a fourth external element that cannot be excluded: the external social and material environment. These elements work together; the person is at the center but the unifying concept is the home. The relationships between these elements work in several directions; for example, the family projects its 
personality onto the house, but the house also models the family's personality, and those of its members.

These elements are not intended to be exclusive; they may be seen as conceptual 'shelves' or 'drawers' that can be used to bring order to the variables and expand the scope of analysis. For example, the personfamily binomial can be used to introduce the ideas of intimacy, subjectivity, lifestyles, care, intergenerational relations, socialization, freedom and many others. The family-dwelling relationship leads to beauty, comfort, hospitality, furniture, appliances, technology, wealth, debt, sustainability, security and identity. The home-society relationship leads to concepts such as neighborhood, village, city, geography, education, commerce, health, family policies, labor market, rights, law, institutions and many others (Heywood, 2005; Somerville, 1997).

The home is a relevant and useful framework for study if it is borne in mind that: (1) people are the core of the study, insofar as they are what gives this community its form; (2) the phenomenon in which we are interested is people's relations with each other and with other people outside the (family) community; (3) the home's ultimate purpose is the people in it: their dignity, prosperity, flourishing and contribution to society, insofar as they are members of that community; (4) this phenomenon implies several dimensions; (5) the actions of the people living in the home, even though they are the outcome of multiple motives, are governed by an internal set of goals; (6) relations in that community take place in a shared space within which the internal relationships are manifested; and (7) they also have a temporal dimension, at least implicitly, between generations, or as a future-looking proposition for its members.

The home can be analyzed as a reality in progress or as a project in development, but what characterizes it above all are the functions it performs. This leads us to try to define the role of people and family in the home, and the role of the home in society.

\section{PEOPLE, FAMILY, HOME}

The home is the 'space open for the quiet flourishing of what is human' (Marcos and Bertolaso, 2018). The home is a means, not an end; it exists for people. ${ }^{6}$

The number of people living in the home is not the most important factor for our approach. In some cases, even one person living alone can form a home. It is true that in this case the internal relationships that take place in a multiperson household are not found, but this does not 
invalidate the analysis from the viewpoint of the home, because people living on their own will, for example, have to keep their dwelling habitable to enjoy a human life, perhaps with the help of other people; they will maintain relationships with their neighbors, take part in the life of the local community, and experience the effects of social inclusion and local policies, in just the same way as a family with several members.

Likewise, our approach to the home can be applied to different groups: nuclear family, extended family, single-parent family, separated parents, compound family, same-sex parents, or even people who live in a home for the elderly or the disabled. ${ }^{7}$ What will change in each case is the type of relationship that develops in them: consequently, the outcomes will vary depending on who these people are and what are their goals and relationships.

People must be considered in all their dimensions, physico-biological or animal (zoon), social or relational (politikon) and rational or spiritual (logon) (Marcos, 2012). Although attention is sometimes focused on certain categories of people (children, women, the elderly) or on a particular facet of the person (paternity or maternity, childhood, housework), the totality of the person should be considered. Obviously, social sciences sometimes treat these people as abstract beings. However, any approach to the home must view people as concrete individuals, "with names and faces' to use the well-coined expression proposed by McVea and Freeman (2005) for relationships within the firm.

The person's place in the home can be analyzed primarily from two viewpoints: privacy and relationality. The home is the place for the person's privacy, to which one retires to keep one's life in order and regain control over it: it is 'the place to which one always returns' (Alvira, 2010), 'that most recondite, private, secure and comfortable place for the self, where it takes shelter from the natural world, to where it belongs as its innermost shelter, and where it addresses the world and the other, opening itself to transcendence' (Patrão Neves, 2018).

In the home we can be as we are, because we are accepted for what we are, not for what we have, give or do. When we show ourselves as we are, we reveal ourselves as vulnerable beings who need material, cognitive or spiritual protection; human vulnerability receives protection on a physical level from the house as a structure and on a personal level from the home's members. So vulnerability means dependence on the help received from others; therefore, it is complementarity and reciprocity. But the home is not just the place where the person's vulnerability is alleviated: 'it is in the home where we find the true expression of the interiority of the human being, a natural base that is necessary in order to carry out the tasks demanded by society' (d'Entremont, 2018). 
However, if all the home provided was intimacy, privacy, many needs that people have would not be met, because people need others not only to satisfy their material needs but also their spiritual needs: to attain self-knowledge. The home is also the place where personal relationships are developed, in which each individual gives of him or herself to others and receives from them. 'Home is that site where relation originally occurs and within which individuals are constituted' (Patrão Neves, 2018).

The home's internal function is given by these relationships, which determine what people seek or expect, perhaps without knowing it; not only something that is given to them by the physical location or the other people, but something that each person gives to him or herself precisely because they are in that place and relate with those people, and something that each person gives to others and, consequently, to him or herself, at the physical, mental, emotional or cognitive level, or the level of values and virtues. This entails rights and responsibilities, work, formal organization (rules, judgment, hierarchy, authority) and informal organization (trust, implicit understanding, putting aside personal criteria to favor the needs of other members), material possessions, human and social capital and many other elements, all of them focused on achieving certain material and spiritual results for the people and the internal community (Allan and Crow, 1989).

The home's members pursue private, personal goals; as we have already said, they seek in the home's privacy and relationality the satisfaction of their most important needs. But in that process they also pursue common, often implicit goals that are shared with the other members. The home is a place (not the only one) where common goods are created, produced by everyone, because everyone participates in their production, and they are consumed or enjoyed by everyone (Argandoña, 2015).

This production and this consumption are not ruled by the laws of exchanges between peers on the market, but are governed by criteria of reciprocity, gratuitousness and gift (Argandoña, 2011). ${ }^{8}$ Reciprocity implies that there is not necessarily a proportionality between what is given and what is received, nor a precise succession in time: no account is kept in the home of what one does for others and what others do for oneself. Gift or gratuitousness means giving without expecting anything in return, either now or in the future, as is the case of caring for young children or disabled members. ${ }^{9}$ This is part of the ethical dimension to which we will refer later. ${ }^{10}$

This brings us to another dimension of the human person: autonomy, the ability to determine for oneself the criteria for taking action and for 
freely accepting the help of others. However, autonomy is the counterpart of dependency: the autonomous person chooses how he or she will put him or herself at the service of those who are vulnerable and dependent - and that is care (Marcos and Bertolaso, 2018). In the home, dependency plus autonomy call to care.

With this, the home becomes a privileged site of reciprocity, solidarity and care, especially for children, the sick, the disabled, the frail and the elderly, but not only for them, because all of its members usually need the care of others. The home is not the only social structure that performs these tasks: the school, the church, some associations, the neighborhood or even companies perform some of them; but the home is probably the most important institution. In the home there is no dichotomy between autonomy and dependency: the person is born totally dependent and needs many years of development and learning, mainly in the home, in order to have the degree of autonomy of a mature person, which he or she will then have to apply to the care of others (Torralba, 2005).

If the home is a community of people, it is these people who bestow value on the home, not just economic value: the home is good because of the service it renders to people, and it acquires its social value through the relationships that exist within the home and with the outer community. This must be the main criterion for determining what is a good and valuable home.

\section{THE HOME AND SOCIETY}

The home cannot be understood in isolation from society. The home forms part of a broader framework that contains society as a whole, together with other people, homes and organizations, and with the physical environment (d'Entremont, 2018), and it is from here that the home's relationships with the exterior arise: the home is 'within but open' (Marcos and Bertolaso, 2018).

Many of these relations are mediated by institutions and organizations (markets, churches, governments, companies) and governed by normative frameworks (laws, regulations, social and ethical norms, customs); for this reason, the home's viewpoint must be taken into account in order to understand many of the problems raised with respect to these institutions, organizations and norms. ${ }^{11}$

The home within a broader society can be viewed from the standpoint of the home or from that of society. When viewed from the latter, we can define its external function as its contribution to the good of society, defined in a very broad sense. This does not mean that the home's 
external function consists of adding new obligations or duties to its internal function: the home's contribution to society's wellbeing and flourishing is to be nothing more and nothing less than a good home. This is inferred from the nature of the internal social function and its responsibilities: reproduction; caring for bodies; raising, caring and educating the new generations; stabilizing and enriching personalities; caring for the elderly, sick and infirm; building the identity of the individuals and reproducing the social identity of the family; developing virtues and values, and many others (González and Iffland, 2014).

This social function is the result not so much of a conscious, deliberate action as a spontaneous, informal but effective order produced by the action of thousands of homes, plus other organizations, institutions, laws and policies (Hayek, 1967). A good society fosters the development of good homes, but the relationship is reciprocal: 'human development and the advancement of society will only be possible if it is based on societies made up of stable families organized in a personalized home environment; this is what will lead to a stable and personalized society' (d'Entremont, 2018). For example, a good society establishes the legal, institutional and cultural framework within which homes can flourish: the constitution, laws and regulations, public and private institutions (legal, health, education, research, business and many others), establishment of the rule of law and markets, taxation and transfer structures, the welfare state, culture, and so on. And the same applies to public and private policies such as the measures for supporting and protecting the home (housing, health, education, pensions, specific taxes and transfers, and so on) and the adequate management of public agencies, among many others.

In this respect, society's duties toward the home should take into account the principle of subsidiarity: what can be done by the lower instance, the family, should not be done by the higher instance, the local, regional or national community or government, and when the lower cannot do it to a sufficient degree, the higher should seek, above all, to support the family's autonomy and initiative (Melé, 2005). This addresses the home's autonomy criterion (which is a reflection of the individuals' autonomy): the fact that the person lives immersed in a complex society and that he or she needs the help of society (and other institutions) does not detract from the fact that he or she should maintain their capability to meet their needs without relinquishing their rights and without being subject to undue control or pressure.

One consequence of this is that the solutions to the home's problems cannot come solely or chiefly from outside, from the society, government 
or experts, but rather, they must integrate the home's intrinsic capabilities. Here we are assuming that the home has a limited but real capability to solve its problems, although not all homes have all the necessary capabilities nor do they have the same capabilities at different times. Thus, the home has a real but limited autonomy that must be grounded on a sufficient degree of freedom, with the resulting moral (and not just legal) responsibility.

The second implication is that the home's response to measures aimed at protecting, assisting and supporting it cannot be merely passive but must actively involve its internal community. The home is inherently dynamic (like all systems in which human beings are involved), and this dynamism has many implications. We will highlight just one: the decisions that are taken at a given time generate learning processes that condition future actions and, therefore, the stability or even the viability of the system, of the home itself. To borrow a term from economics, if we can talk of a stable equilibrium of the home's dynamism over time, this equilibrium will be determined by external resources or constraints (for example, the educational system, society's values, the economic framework and family policies) but, also and decisively, by the internal resources and, above all, by the consistency between all these elements, which will be governed by its members' rules of engagement, between one another and with the outside community. Taking this into account is one of the many ways of putting the home-based approach at the core of the study of social problems.

Or, to put it another way, solutions to the home's problems cannot be merely technical. If the goal of the home is the development and dignity of the person, then experts who propose measures and politicians who endorse them must consider whether they help people to flourish and homes to become stronger, and not just whether they solve economic, health or other problems. ${ }^{12}$ They must also take into account all the different dimensions of the problem: psychological, economic, relational, ethical, and so on. ${ }^{13}$ In short, since the home has a social function, it is important that the public or private measures adopted enhance its ability to perform its task, fostering its members' cooperation so that they take responsibility for their own lives and fulfill their responsibilities toward others, with such assistance as may be required in each case. This will mean not supplanting people's initiative and resources but complementing them when it is necessary; and also involving other private agents and society as a whole, not just the government. 


\section{DIMENSIONS OF THE HOME}

As stated above, the home has numerous dimensions, so any study of the home must be multidimensional. What follows is only a quick tour of some of these dimensions. The purpose of this section is merely to show how different aspects or components of the home's problems can be included in the analysis, linking them with other dimensions.

\section{The Temporal Dimension}

At any given time, the home is portrayed as a static, given reality, but in fact it is essentially dynamic. It is a set of processes that take place in time. It often mimics the stages of the person's life: more proactive in the early years, providing support and encouragement in maturity, and with further aspects in later life (Werner et al., 1985). In turn, people produce changes in the environment they move in, for example in the dwelling, while their body and age change. As we said before, people aspire to autonomy but they are naturally dependent and vulnerable, and coping with this fact also conditions the physical framework in which they move (Frezza et al., 2017).

The consideration of time is important, as the processes that take place within the home, especially learning and maturing, need time. The periods involved are often very long, much longer than other human activities. Patience is a virtue that is even more necessary in the home than in other settings, both because most of the exchanges are based on gratuitousness and gift, and because its social function spans much longer periods than, for example, that of governments, companies or voluntary associations. The home-based approach entails considering long periods of time. For example, the consequences of losing one's dwelling, even if it is only temporarily, will be felt for many years on everyone's health, on the children's lives, the development of their abilities, the acquisition of habits, their performance at school and work, the future stability of their marriages and the stability of society (Burns, 2018; Dunn, 2000), and the same can be said of the consequences of a broken or dysfunctional family (Regnerus, 2018).

\section{The Spatial Dimension}

The home has an obvious spatial dimension that has been extensively discussed in the literature, ${ }^{14}$ which refers not only to the physical space - the house, abode, shelter or dwelling - but also to the psychological and cultural space-sharing places, creating, preserving and 
developing an identity ${ }^{15}$ — and the geographical, physical, cultural, economic or political environment (Buttimer and Seamon, 2015; Cuba and Hummon, 1993; d'Entremont, 2018; Reutebuch, 2015). 'House is a material object but home is a relation ... home is an emotionally based and meaningful relationship between dwellers and the dwelling places' (Karjalainen, 1993, p. 71). 'Thus, while the idea of home can be viewed as a universal concept, the experience of home is socially and culturally determined' (Fox O'Mahony, 2013, p. 165).

The spatial dimension encompasses, first of all, the dwelling, the house: a space within which its members live their lives. The house is isolated, separated by its walls, which enclose the space for privacy; but the walls also have doors and windows, which open the house to the exterior and allow selective interaction; outside the house is the immediate environment, the neighborhood, village or town, and beyond that, the home takes the form of collective memory and group identity (Bratt, 2002, 2003). Yet the boundary between the home and its environment is not well defined. In past times, and even today in many places, ordinary life often runs on the street around the house or in the houses of neighbors, giving validity to the phrase 'it takes a village to raise a child'. Today, especially in large cities, the home is almost closed to the nearby community, although perhaps more open to remote social networks and virtual environments: the concepts of space and relatedness are changing.

'Of all places, the home has a particularly powerful symbolic and psychological significance ... the home is more than a place in which an individual resides but rather a unique place where a person's past, present, and future selves are reflected and come to life' (Graham et al., 2015 , p. 346). The literature on the meaning of home offers many insights for understanding its functions as a center of family life; a place of retirement, security and relaxation, freedom and independence; an opportunity for self-expression and social status; a place of privacy, continuity and sojourn, of control over one's decisions and freedom to act and for reflection on self-realization; a support for work and leisure; a space for ontological security, to nurture relationships; a place of nourishment, play and growth for children; a central hub from which one leaves for other places and to which one returns; a nexus of roots and so on. '[T]he originality of home does not rely on being an object to be enjoyed ...; it consists of being a condition for human activity or the beginning of it, separate from the logic of possession and enjoyment ... and within a logic of giving' (Patrão Neves, 2018-following Lévinas, 1979).

The home also has a functional dimension, which is the first that is seen when we observe an active house. The home continues in the 
instruments (furniture, ornaments and appliances) that form a reference plexus for the person. Taken together, they make up the home's human world (Highmore, 2011; Miller, 2001): 'home is where the heart is' (Fox O'Mahony, 2013, p. 164). The existence of this material world also implies the need to care for it, whether it is the responsibility of the people who live in the house or of external collaborators.

The spatial dimension combines with the temporal one: the dwelling 'cannot be defined except as a presentation of a general plan for meeting future needs' (Douglas, 1991, p. 295). This again shows the complexity of interrelations within the home.

\section{The Economic Dimension}

Many human activities have an economic dimension, insofar as they involve making decisions about the use of scarce means that have alternative uses, to use Lionel Robbins's classic definition of economics (1932). Here, we will only look at a number of economic variables that impact on the home's life: the home 'has' an economic dimension, but, unlike companies, it 'is' not an economic organization. ${ }^{16}$ Our main interest in economics is for the instrumental role it plays in daily life. ${ }^{17}$ Here we will mention just a few aspects of the economic dimension:

- Wealth. The dwelling is an asset, an investment and a consumer commodity, which renders services that satisfy immediate needs, generates a financial yield and provides access to other benefits such as hedging and collateral. The family's balance sheet contains assets and rights offset by liabilities, debts and commitments, the balance of which will give the net worth. The home's economic image at any given moment in time is centered mainly on the house. ${ }^{18}$

- Income and expenses. In the home, flows of goods and services are generated that enter and leave the home-what we could call its cash-book. The family is a provider of services to society (labor, savings, human capital, culture, innovation, creativity), it pays taxes and gives transfers, and in turn it receives from society income, other services and transfers (pensions, unemployment benefits, gifts). The development of these items defines the family's standard of living, savings, indebtedness, solvency and liquidity.

- Motivation. The decision-making processes within the home impact on the production of goods and services, labor supply, investment, consumption and savings, and also on fertility and many other aspects (Doepke and Tertilt, 2016). The plethora of varied and 
changing human motivations can be grouped in three main blocs: extrinsic, in which the agent (the home and its members) is driven by the external outcome of the action; intrinsic, in which the agents are driven by expected outcome of their actions on themselvesactions that they themselves originate (acquisition of knowledge and abilities, satisfaction); and transcendent or prosocial, in which the agents are driven by the results of their decisions on others (Argandoña, 2008; Pérez López, 1993).

These three motivations are present in all human decisions. Economics usually pays particular attention to extrinsic motivation, sometimes together with intrinsic motivation; their importance should not be underestimated, because the survival of the home and its material progress depends on them. But what distinguishes the home from other economic agents is the predominance of the transcendent motivations: economic (prices, costs, returns, profit) and psychosocial (identity, security, stimulus, emotional ties, meaning) variables are relevant, but in the family the moral variables (the consequences of decisions for the agent's and other people's learning and the agent's moral learning) take on special significance. The home is probably the chief seat of the gift economy; this explains why intergenerational transfers within the home are grounded on solidarity. ${ }^{19}$

- Family business. The home may also be associated to a business that produces goods and services to sell on the market, just like other businesses, but with significant differences in their motivation, governance, management and results. Initially, the business was another activity performed by the farming family, tied to its self-sustenance. However, with time, it took on an existence of its own, becoming increasingly similar to corporate enterprise.

The relationships between the family business and the family are complex, but they often preserve many of the values of the home such as integrity, honesty and transparency, kindness and respect, working for the benefit of the communities in which it operates, unity and the sense of responsibility (Aronoff and Ward, 2016; Poza and Daugherty, 2013; Tàpies and Ward, 2008).

- Joint production and consumption. The family is a partnership whose purpose includes to perform joint consumption and production, thanks to its internal division of labor, which enables it to share comparative advantages and economies of scale, investment coordination, adequate risk management and care of children, who are a common good of the family (Browning et al., 2013; Zamagni, 2018). 
- Work in the home. The joint production of material and nonmaterial goods is achieved by means of a necessary cooperation between the home's members to do something that no member could do on his or her own, or would find it very hard to do ${ }^{20}$ In this task, they are also assisted by external workers. ${ }^{21}$ The work done in the home does not consist solely of doing things but also and mainly of transforming people.

- Common goods and gifts. As stated above, the goods that are produced in the home are material private goods, whose consumption or enjoyment by one person excludes others. But there are also goods of a higher category; the home generates collective, shared and common goods for its members and for other people. The members of the home contribute to producing these common goods with their activity and with their relationships: everyone contributes goods and everyone benefits from them, although not in the same proportion, in a process that sometimes is a process of exchange and other times a process of giving (Argandoña, 2015).

Mary Douglas (1991) states that the home is sustained by solidarity; if this fails, opportunist, free-riding behaviors strip this collective good, which is created by the selfless action of others, supervised or watched by all and subject to rules of play intended to allow fair access by everyone to what the home produces. Douglas concludes that the home possesses a complex coordination system that is different from the mechanisms of market and political action.

\section{The Ethical Dimension}

All human actions have an ethical content, whether positive or negative, but this is more patent in the home, which is the first place where one learns and practices morality. This is particularly important for children: the home is the first school of virtues, operative habits acquired by means of excellence-oriented practices that model people's character.

To some extent, studying an issue from the viewpoint of the home requires taking into account all the consequences on all people, and one of these consequences is moral learning, the acquisition of virtues. The exercise of virtue has four dimensions (Alzola, 2015; Argandoña, 2016b): (1) cognitive: a virtuous person 'perceives a situation rightly-that is, notices and takes appropriate account of the salient features of a situation' (Hartman, 2008, p. 322); (2) emotional: virtues are 'dispositions not only to act in particular ways but also to feel in particular ways' (MacIntyre, 1984, p. 149); (3) motivational: virtues are not primarily acts 
but dispositions that arise from the agent's intentions or motivations and from the formation of habit; (4) behavioral: virtues 'will sustain us in the relevant quest for the good, by enabling us to overcome the harms, dangers, temptations and distractions which we encounter, and which will furnish us with increasing self-knowledge and increasing knowledge of the good' (MacIntyre, 1984, p. 219).

However, ethics does not consist solely of the acquisition and development of virtues, but must also entail the observance of norms (general norms of the community, but above all the rules of coexistence and relationship with which the internal community endows itself), and the pursuit of goods or benefits (many goods, of very different natures) (Polo, 1996b). The ethical dimension presents the home as a microcosm of society, because it seeks to attain, on a micro scale, what society should achieve on the macro scale.

\section{Other Dimensions}

There are also other dimensions that we have not considered here: legal (rights and duties inside and outside the home, legal protection); cultural (the cultural models of society influence the culture of the home, but the home is also a creator of culture in society); communicative (communication in its multiple forms is key, inside the home and with the outside); political (the home is a political agent, it is the object of political decisions, and is influenced by politics); psychological (as explained in the discussion of the spatial dimension); sociological (also mentioned, both within the family and in its relations with its environment); religious and theological (the home is the first school of religious convictions and practices, which also makes it a sphere of study for theology); and many others.

\section{CONCLUSIONS}

In our modern societies, the different fields of knowledge have evolved along separate paths, applying different assumptions, languages, techniques and methods. This has produced enormous progress in science, but at the cost of a loss of shared vision and difficulties in attaining mutual understanding. When problems are complex, as is often the case in social sciences, it would be helpful to have some common playing field in which we could all move, perhaps not comfortably, but at least confidently and effectively. It would not be acceptable for one discipline to impose itself on the others in this task, and neither would it be the 
most suitable approach, as it would exclude important aspects of the reality under study. ${ }^{22}$

In this chapter, we have proposed the home as an element that can be used to put order into the analysis of certain social problems, when the study's central focus is the person as member of a small community (the family, in broad terms). An understanding of the internal relationships in that community can enable identification of the various dimensions of a problem. When people and their sphere of physical, psychological, social and moral coexistence are taken as a unit of analysis, the various relevant disciplines can be brought adequately into play. What makes the home the center of analysis is the existence of an internal-and externalsocial function belonging to that community, which provides the rationale for its existence.

To bring our reflections to a conclusion, we can ask two questions. The first is: what makes a home a 'good' home? The answer will be given by each person on the basis of his or her particular anthropological, social and ethical background. We will have lots of answers, often inconsistent and sometimes clearly contradictory. However, this should not lead us to perplexity, to shrugging our shoulders or relativism.

Putting the home at the center of analysis means explicitly stating the premises, showing the definitions, presenting the evidence, submitting the techniques for review and evaluating the models, trying to understand the other scientists not only from one's own outlook but also from theirs. This does not guarantee agreement but it does provide a basis for understanding. If the study is dynamic - that is, if it includes the laws of evolution of reality such as learning processes and knowledge dissemination, changes in attitudes and values, and the development of virtues-we can understand why some proposals will probably not produce the desired results or will take us in untenable directions. Consequently, as stated above, the analysis must be multidimensional, multidisciplinary, integrative, open, dynamic and global, albeit subject to individual corroboration in each location and situation.

The question of what a 'good' home is will always be present, in one way or another, not only in the minds of academicians but also of politicians, rulers, opinion leaders, social reformers and citizens in general. The answer we give will always be conditional upon the second, no less important question: does it serve any purpose to define an ideal, when that ideal is not even remotely fulfilled for billions of people around the world?

Our answer is that an ideal can serve as a link between what 'is', the crude reality, and what 'should be' (Neiman, 2008). In the end, academicians, politicians, communicators and citizens have to consider what kind 
of home they want and what they expect from this institution. This chapter does not attempt to give answers to these questions, but tries to offer keys to help find and analyze them. That is why we believe that a broad, descriptive, open, multidisciplinary approach to the home is necessary to adequately address the many problems facing our societies, be they advanced, emerging or developing. That is also the object of this book.

\section{NOTES}

1. This chapter forms part of the research performed by the Home Renaissance Foundation and the CaixaBank Chair of Corporate Social Responsibility, IESE Business School, University of Navarra. Maria Sophia Aguirre, Elisabeth Andras, María Pía Chirinos, Marta Elvira, Helen Keefe, Rosemary Keenan, Rosario Peris, Susan Pitfield, Maria Julia Prats and the authors of the chapters of this book made interesting suggestions, which I am grateful for. Obviously, the ultimate responsibility is mine alone.

2. In Peru, during those years, coca growing was done mostly by boys aged 12 to 14 , because it requires a level of physical effort that younger children are not capable of, because the age of criminal responsibility is 15 , and because in that way parents avoided any direct involvement and could not be convicted of being accomplices to illegal behavior (Sviatschi, 2017). This is why we say that the unit of analysis must be the home (people, the family and the physical environment), and not people considered individually, nor the village or the country.

3. If society is understood as a network, the nodes of this network could be individual people-for example, in the case of interactions between teenagers through a social medium. However, in many other cases, the node must be the family unit-for example, when parents try to mediate in or control these relationships, or when they are interested in the impact that they may have on the home.

4. This is logical, as the home is a sphere to which we humans have devoted much of our best effort for many centuries. This will lead the researcher to recognize the diversity and creativity of the home in different settings and cultures.

5. See Easthope (2004) for a partial but interesting attempt.

6. Family policies, for example, seek to help or develop the people who make up the family, precisely because they are members of a family.

7. Usually a barracks or a hotel is not considered a home, because the intention of continuity is lacking.

8. Contributing to producing these common goods implies positive learning, an improvement in people's moral quality; it is a duty but also a right (Argandoña, 2015).

9. Care has several meanings in the home, as in ordinary life: the home looks after people because it protects them, and this is possible because the home is made and organized with care, and because in it people apply care in their relations with one another.

10. This approach seeks to go beyond the individualistic view of the family, focused, for example, on the utility maximization paradigm (Zamagni, 2018), or on the culture of rights before duties, particularly when rights are conceived as the outcome of a confrontation. In the home, as in any other human organization, there may be domination, oppression and servitude, but to present this as a definition of what a home is, is to destroy it, above all because it is always possible to find arguments to define a relationship as marked by actual, potential or intentional conflict.

11. This is usually not taken into account when designing public policies: pension reform, for example, usually takes into account the economic impact on present and future pensioners, but not on the home in which they or their offspring live (cf. Davis and Lastra, 2018). 
12. As Polo (1996a) points out, the often unforeseen, but also unavoidable consequences of applying purely technical solutions to human problems are: (1) segmentation, due to the lack of a vision of the whole; (2) perverse effects, which may appear in other spheres, because we are not able to manipulate the means without giving rise to dangerous collateral effects, because there are no unconditioned principles from which we can deploy the practical action, and because we cannot guarantee the consistency of our uncoordinated projects; (3) anomy, the despondency of those who have no guidelines for action, only stimuli; and (4) social entropy, when institutions lose their function (cf. Argandoña, 2016a).

13. Unfortunately, many family policies, although often well-intentioned, have only partial objectives. For example, Olivetti and Petrongolo (2017, p. 212) studied family policies in a large group of developed countries in recent decades and concluded that the objectives of these policies are relatively narrow: 'most family policies are intended to encourage female labor supply. For example, subsidized child care seeks to provide direct subsidies for maternal child care. Maternity leave seeks to enable mothers to stay attached to the labor market during temporary interruptions of employment ... Similar arguments can be made for flexible or part-time work arrangements.'

14. For example, in the works on environmental psychology espoused by Irwin Altman and his disciples and co-authors, compiled in the series 'Human Behavior and Environment'; also in the sociological studies of the family and relationships (cf. the pioneering work of Smart, 2007; also May, 2011), and in the works of W. Richard Scott on organizations as open systems; cf. Scott and Davis (2006). Marcos and Bertolaso (2018) review the treatment given to this issue in recent philosophical literature, taking Heidegger (1993) as a starting point, and Patrão Neves (2018) does the same following Lévinas (1979).

15. There is a very extensive literature on this subject-for example, cf. Altman (1975); Israel (2003); Kearns et al. (2000); Marcus (1995); Sternberg (2009); Tuan (1977); Worsley (2011).

16. The home needs to preserve its economic sustainability, just like all human organizations, but the way it does this differs considerably from other organizations, as we will see further on.

17. Economic science has developed an economic theory of the family, which accounts for the decisions made in the home by applying the basic assumptions of economics (Zamagni, 2018). For an analysis of decisions and their consequences in the economic theory of the family, see Browning et al. (2014) and Greenwood et al. (2016); Becker (1981) is a classic on the subject. See criticisms of the economic theory of the family in Aguirre (2006) and Zamagni (2018), among others.

18. Home ownership varies considerably from one country to another, as a consequence of their culture, their history (sometimes as a guarantee of independence from the state), their institutions (inheritance, capital markets, taxation) and their economic vicissitudes.

19. The intergenerational transfers between homes, whether voluntary or brokered by the state, may also have a solidarity component (donations, inheritance), although not always - cf. Davis and Lastra (2018) for the case of retirement pensions.

20. Common actions in the family are characterized by three elements: they cannot be undertaken without the cooperation of the members of the family; each agent is accountable for his or her cooperation; and all must act in coordination, with a common objective-cf. Zamagni (2018).

21. On work in the home, cf. Aguirre (2014); Brodeur (2012); Eichler and Albanese (2007); Parente et al. (2000); Russo (2011). On the philosophical foundations of work, and work in the home, cf. Chirinos (2006).

22. Economics, for example, has been accused of imperialism by other social sciences-cf. Boulding (1969); Fine (2000). 


\section{REFERENCES}

Aguirre, M.S. (2006), 'Marriage and the family in economic theory and policy', Ave Maria Law Review, 4 (2), 435-65.

Aguirre, M.S. (2014), 'Socioeconomic impact of the work of the home', in A.M. González and C. Iffland (eds), Care Professions and Globalization: Theoretical and Practical Perspectives, New York, NY, USA: Palgrave Macmillan pp. $133-45$.

Allan, G. and G. Crow (eds) (1989), Home and Family: Creating the Domestic Sphere, London, UK: Macmillan.

Altman, I. (1975), The Environment and Social Behavior: Privacy, Personal Space, Territory, and Crowding, Monterey, CA, USA: Brooks/Cole.

Alvira, R. (2010), El lugar al que se vuelve: Reflexiones sobre la familia, Pamplona, Spain: Eunsa.

Alzola, M. (2015), 'Virtuous persons and virtuous actions in business ethics and organizational research', Business Ethics Quarterly, 25 (3), 287-318.

Argandoña, A. (2008), 'Integrating ethics into action theory and organizational theory', Journal of Business Ethics, 78 (3), 435-46.

Argandoña, A. (2011), 'Beyond contracts: love in firms', Journal of Business Ethics, 99 (1), 77-85.

Argandoña, A. (2015), 'The common good, stakeholder theory and the theory of the firm', in M. Schlag, J.A. Mercado and J.E. Miller (eds), The Challenge of Charity. Freedom and Charity Working Together, Rome, Italy: Edusc, pp. 195-216.

Argandoña, A. (2016a), 'Three ethical dimensions of the financial crisis', in A.G. Malliaris, L. Shaw and J. Shefrin (eds), The Global Financial Crisis and its Aftermath: Hidden Factors in the Meltdown, New York, NY, USA: Oxford University Press, pp. 413-28.

Argandoña, A. (2016b), 'Humility and decision making in companies', presented at the conference 'Humility: Reflections on Its Nature and Function', University of Oklahoma, 20-21 October.

Aronoff, C. and J. Ward (2016), Family Business Values: How to Assure a Legacy of Continuity and Success, 2nd edn, New York, NY, USA: Palgrave Macmillan.

Becker, G. (1981), A Treatise on the Family, Cambridge, MA, USA: Cambridge University Press; expanded edition 1991.

Boulding, K.E. (1969), 'Economics as a moral science', American Economic Review, 59 (1), 1-12.

Bratt, R.G. (2002), 'Housing and family wellbeing', Housing Studies, 17 (1), 13-26.

Bratt, R.G. (2003), 'Housing: the foundation of family life', in R.M. Lerner, F. Jacobs and D. Wertlieb (eds), Handbook of Applied Developmental Science: Promoting Positive Child, Adolescent, and Family Development through Research, Policies, and Programs, vol. 2, Enhancing the Life Chances of Youth and Families, Thousand Oaks, CA, USA: Sage, pp. 445-68.

Brodeur, A.F. (2012), 'A brief history of housework, 1900 to present', Home Renaissance Foundation Working Paper, no. 41, London, UK. 
Browning, M., P.-A. Chiappori and A. Lewbel (2013), 'Estimating consumption economies of scale, adult equivalence scales, and household bargaining power', Review of Economic Studies, 80 (4), 1267-303.

Browning, M., P-A. Chiappori and Y. Weiss (2014), Economics of the Family, Cambridge, UK: Cambridge University Press.

Burns, H. (2018), 'The impact of the home environment on children's health and cognitive and social development', Chapter 4, this volume.

Buttimer, A. and D. Seamon (2015), The Human Experience of Space and Place, 2nd edn, London, UK: Routledge.

Chirinos, M.P. (2006), Claves para una antropología del trabajo, Pamplona, Spain: Eunsa.

Cuba, L. and D.M. Hummon (1993), 'A place to call home: identification with dwelling, community, and region', The Sociological Quarterly, 34 (1), 111-31.

Davey Smith, G., D. Dorling and M. Shaw (2001), Poverty, Inequality and Health in Britain, 1800-2000: A Reader, Bristol, UK: Policy.

Davis, E.P. and R.M. Lastra (2018), 'Pension provision, lifetime financial sustainability, care and dignity in old age: legal and economic issues', Chapter 7 , this volume.

d'Entremont, A. (2018), 'Spatial relationality and domesticity: reality and functions of the home from a human geography perspective', Chapter 8 , this volume.

Doepke, M. and M. Tertilt (2016), 'Families in macroeconomics', in J.B. Taylor and H. Uhlig (eds), Handbook of Macroeconomics, vol. 2B, Amsterdam, the Netherlands: Elsevier, pp. 1789-891.

Douglas, M. (1991), 'The idea of a home: a kind of space', Social Research, 58 (1), 287-307.

Dunn, J. (2000), 'Housing and health inequalities: review and prospects for research', Housing Studies, 15 (3), 341-66.

Easthope, H. (2004), 'A place called home', Housing, Theory and Society, 21, 128-38.

Eichler, M. and P. Albanese (2007), 'What is household work? A critique of assumptions underlying empirical studies of housework and an alternative approach', Canadian Journal of Sociology, 32 (2), 227-58.

Fine, B. (2000), 'Economics imperialism and intellectual progress: the present as history of economic thought?', History of Economics Review, 32 (1), 10-35.

Fox O'Mahony, L. (2013), 'The meaning of home: from theory to practice', International Journal of Law and Built Environment, 5 (2), 156-71.

Frezza, G., H. Keefe and M. Bertolaso (2017), 'Work of the home and social relationships as a guide to domestic care for the elderly', in F. Cavallo, V. Marletta, A. Monteriù and P. Siciliano (eds), Ambient Assisted Living, New York, NY, USA: Springer pp. 79-86.

George, R. (2015), 'Five pillars of a decent and dynamic society', in J. Stoner and H. James (eds), The Thriving Society: On the Social Conditions of Human Flourishing, Princeton, NJ, USA: The Witherspoon Institute, pp. 1-8.

González, A.M. and C. Iffland (eds) (2014), Care Professions and Globalization: Theoretical and Practical Perspectives, New York, NY, USA: Palgrave Macmillan. 
Graham, L.T., S.D. Gosling and C.K. Travis (2015), 'The psychology of home environments: a call for research on residential space', Perspectives on Psychological Science, 10 (3), 346-56.

Greenwood, J., N. Guner and G. Vandenbroucke (2016), 'Family economics writ large', working paper 2016-026A, St. Louis, MO, USA: Federal Reserve Bank of St Louis (forthcoming, Journal of Economic Literature).

Hartman, E.M. (2008), 'Socratic questions and Aristotelian answers: a virtuebased approach to business ethics', Journal of Business Ethics, 78 (3), 313-28.

Hayek, F.A. (1967), Studies in Philosophy, Politics and Economics, Chicago, IL, USA: University of Chicago Press.

Heidegger, M. (1993), 'Building, Dwelling, Thinking', Basic Writings, New York, NY, USA: Harper, pp. 344-63.

Heywood, F. (2005), 'Adaptation: altering the house to restore the home', Housing Studies, 20 (4), 531-47.

Highmore, B. (2011), Ordinary Lives: Studies in the Everyday, London, UK: Routledge.

Israel, T. (2003), Some Place Like Home: Using Design Psychology to Create Ideal Places, New York, NY, USA: Wiley/Academy.

Karjalainen, P.T. (1993), 'House, home and the place of dwelling', Scandinavian Housing and Planning Research, 10, 65-74.

Kearns, A., R. Hiscock, A. Ellaway and S. Macintyre (2000), "Beyond four walls": the psycho-social benefits of home: evidence from West Central Scotland', Housing Studies, 15 (3), 387-410.

Lévinas, E. (1979), Totality and Infinity: An Essay on Exteriority, The Hague, Boston and London: Martinus Nijhoff Publishers.

MacIntyre, A. (1984), After Virtue: A Study in Moral Theory, 2nd edn, Notre Dame, IN, USA: Notre Dame University Press.

MacIntyre, A. (1990), Three Rival Versions of Moral Inquiry: Encyclopaedia, Genealogy, and Tradition, Notre Dame, IN, USA: Notre Dame University Press.

Marcos, A. (2012), 'Dependientes y racionales: la familia humana', Cuadernos de Bioética, 23 (77), 83-95.

Marcos, A. and M. Bertolaso (2018), 'What is a home? On the intrinsic nature of a home', Chapter 2, this volume.

Marcus, C. Cooper (1995), House as a Mirror of Self: Exploring the Deeper Meaning of Home, Berkeley, CA, USA: Conari Press.

May, V. (ed.) (2011), Sociology of Personal Life, Basingstoke, UK: Macmillan.

McVea, J.F. and R.E. Freeman (2005), 'A names-and-faces approach to stakeholder management', Journal of Management Inquiry, 14 (1), 57-69.

Melé, D. (2005), 'Exploring the principle of subsidiarity in organisational forms', Journal of Business Ethics, 60 (3), 293-305.

Miller, D. (ed.) (2001), Home Possessions, Oxford, UK: Berg.

Neiman, S. (2008), Moral Clarity: A Guide for Grown-up Idealists, Boston, MA, USA: Harcourt.

Olivetti, C. and B. Petrongolo (2017), 'The economic consequences of family policies: lessons from a century of legislation in high-income countries', Journal of Economic Perspectives, 31 (1), 205-30. 
Parente, S.L., R. Rogerson and R. Wright (2000), 'Homework in development economics: household production and the wealth of nations', Journal of Political Economy, 108 (4), 680-87.

Patrão Neves, M. (2018), 'Self and others: home as a cradle of a non-violent relationship', Chapter 3, this volume.

Pérez López, J.A. (1993), Fundamentos de dirección de empresas, Madrid, Spain: Rialp.

Polo, L. (1996a), Sobre la existencia cristiana, Pamplona, Spain: Eunsa.

Polo, L. (1996b), Ética: hacia una versión moderna de los temas clásicos, Madrid, Spain: Unión Editorial.

Poza, E.J. and M.S. Daugherty (2013), Family Business, 4th edn, Mason, OH, USA: South-Western Cengage Learning.

Regnerus, M. (2018), 'Reproducing homes: intergenerational transmission of marriage and relationship legacy', Chapter 5, this volume.

Reutebuch, T. (2015), 'Assets and neighboring: an exploration into household assets and efforts to be a good neighbor', The Journal of Sociology and Social Welfare, 29 (4), 117-30.

Robbins, L. (1932), An Essay on the Nature and Significance of Economic Science, London, UK: Macmillan.

Russo, M.T. (2011), 'Relational dimensions of housework: how to reconcile the gift with the market', Home Renaissance Foundation Working Paper, no. 29, London, UK.

Sclar, E.D. and M.E. Northridge (2003), 'Slums, slum dwellers, and health', American Journal of Public Health, 93 (9), 1381.

Scott, W.R. and G.F. Davis (2006), Organizations and Organizing: Rational, Natural and Open System Perspectives, Abingdon, UK and New York, NY, USA: Routledge.

Shaw, M. (2004), 'Housing and public health', Annual Review of Public Health, 25 (1), 397-418.

Smart, C. (2007), Personal Life, Hoboken, NJ, USA: Wiley.

Somerville, P. (1997), 'The social construction of home', Journal of Architectural and Planning Research, 14 (3), 226-45.

Sternberg, E.M. (2009), Healing Spaces: The Science of Place and Well-Being, Boston, MA, USA: Belknap Press.

Sviatschi, M.M. (2017), 'Making a Narco: childhood exposure to illegal labor markets and criminal life paths', Job Market Paper, Columbia University, accessed 22 March 2017 at http://www.micaelasviatschi.com/wp-content/ uploads/2016/05/jmpMMicaSviatschi.pdf.

Tàpies, J. and J.L. Ward (eds) (2008), Family Values and Value Creation: The Fostering of Enduring Values Within Family-Owned Businesses, Houndmills, UK: Palgrave Macmillan.

Torralba, F. (2005), ¿Qué es la dignidad humana? Ensayo sobre Peter Singer, Hugo Tristram Engelhardt y John Harris, Barcelona, Spain: Herder.

Tuan, Y. (1977), Space and Place: The Perspective of Experience, Minneapolis, MN, USA: University of Minnesota Press.

Werner, C.M., I. Altman and D. Oxley (1985), 'Temporal aspects of homes: a transactional perspective', in I. Altman and C. Werner (eds), Home Environments, New York, NY, USA: Springer Science+Business Media, pp. 1-30. 
Worsley, L. (2011), If Walls Could Talk: An Intimate History of the Home, New York, NY, USA: Walker and Company.

Zamagni, S. (2018), 'The family and economic theorizing', Chapter 6, this volume. 
Antonio Argandoña - 9781786436573 Downloaded from PubFactory at 04/26/2023 03:36:14PM via free access 